\title{
Long term results of operation for shrinking pleuritis with atelectasis
}

\author{
LEIF DERNEVIK, PANTALEI GATZINSKY
}

From the Department of Thoracic and Cardiovascular Surgery, University of Göteborg, Sahlgrenska Sjukhuset, Göteborg, Sweden

ABSTRACT During 14 years 34 patients were operated on for shrinking pleuritis with atelectasis. They were followed up after one to 14 years (mean 6.0) by interview, chest radiography, and spirometry. Most were in good condition, but a reduction in vital capacity had occurred in eight and in $\mathrm{FEV}_{1}$ in 15 patients. Radiographs were normal in 28 patients except for small pleural or parenchymal fibrotic changes. One patient had a suspected recurrence of shrinking pleuritis with atelectasis after nine years, suggesting continuation of the disease process despite operation.

During 1970-83 34 patients with shrinking pleuritis with atelectasis were observed and operated on. In this disease thickening of the visceral pleura causes compression atelectasis of part of the lung.'

Asbestos exposure has been suggested as a likely factor in the causation of this lesion and the coincident parietal pleural plaques. ${ }^{23}$ In general such parietal plaques are situated opposite the lesion in the lung. The surface of the plaques is often somewhat rough and local irritation from the plaque on the adjacent part of the lung surface could be expected to cause the pulmonary reaction. As these plaques are not extirpated during the operation there is a possibility that shrinking pleuritis with atelectasis might recur. At the same time, asbestos can increase the risk of malignancy in smokers, ${ }^{45}$ and most of our patients were smokers.' We therefore planned a follow up study to examine the rate of recurrence of shrinking pleuritis with atelectasis and the risk of malignancy in patients operated on for this condition and also evaluate their subsequent respiratory function.

\section{Patients and methods}

The follow up examination was performed from January to September 1984. There were 33 men aged 43-74 years (mean 62.3) and one woman aged 61 years at the time of follow up. Thirty two patients

Address for reprint requests: Dr Leif Dernevik, Department of Thoracic and Cardiovascular Surgery, Sahlgrenska Sjukhuset, S-413 45 Göteborg, Sweden.

Accepted 16 January 1985 were treated by decortication and two by resection of a lobe. The mean follow up time was six years (range 1-14). Follow up was after at least five years in 22 patients. No patient had had continued exposure to asbestos after the operation, but nine admitted continued smoking.

All 34 patients were asked to participate in the study, which comprised an interview, chest radiography, and spirometry. Five patients reported good health without any complaints and did not want to take part in any examination, so that radiography and spirometry were performed in only 29 patients.

\section{Results}

\section{SYMPTOMS}

Fifteen of 34 patients were symptomless before operation, the shrinking pleuritis with atelectasis being detected at routine examination. Only one patient of the 19 who had various pulmonary symptoms before operation still had cough after the operation. In all other patients the symptoms had disappeared. Seven patients who had no symptoms before operation, however, reported cough after operation, with an asthmatic component in some cases. Four patients had cough and dyspnoea. Six of these 11 patients with symptoms were smokers. The only patient with severe symptoms at follow up was the woman. She had been symptomless before operation but later developed severe asthmatic bronchitis with reduced spirometric volumes, and radiographic examination showed hyperinflated, emphysematous lungs. She was a cigarette smoker and unable to stop smoking. 

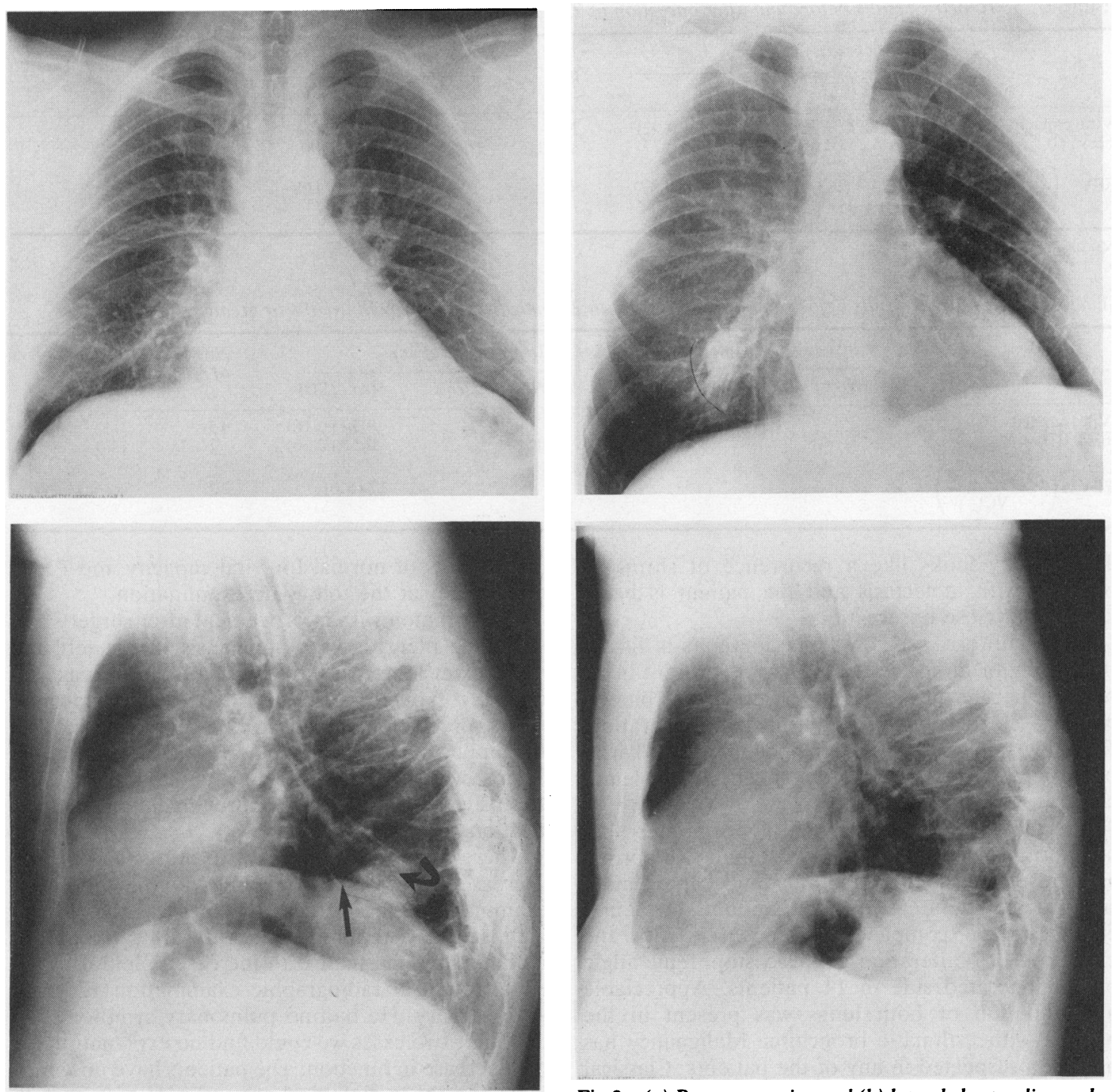

Fig 1 (a) Posteroanterior and (b) lateral chest radiographs, showing shrinking pleuritis with atelectasis in the left lower lobe. The lesion is on the diaphragm and only visible in the lateral view. A characteristic "comet tail" (curved arrow) and areas with compensatory emphysema (straight arrow) are seen.

RADIOLOGICAL EXAMINATIONS

All 29 patients examined by radiography showed total disappearance of the pulmonary opacity caused by shrinking pleuritis with atelectasis. In one patient, operated on for a lesion on the left side (fig 1), there was a diffuse opacity of about $4 \mathrm{~cm}$ in diameter in the anteromedial part of the right lower lobe (fig 2). This was first seen nine years after the

Fig 2 (a) Posteroanterior and (b) lateral chest radiographs of the same patient as in figure 1 nine years after operation. A suspected recurrence of shrinking pleuritis with atelectasis can be seen in (a). Note the adjacent compensatory emphysema (marked).

decortication operation. Radiographs taken two years previously had shown only slight fibrotic changes in the lungs and slight loss of volume on the operated side, with elevation of the left diaphragm. Bronchoscopy and cytological examination of sputum showed no abnormality, and after seven months of observation the opacity is somewhat smaller. Because of this the likelihood of tumour is considered minimal. The patient refuses exploration. 
Table 1 Spirometric results before and after operation in 25 patients

\begin{tabular}{|c|c|c|c|c|c|c|}
\hline & \multicolumn{2}{|c|}{ Mean $(S D)$ values } & \multirow{2}{*}{$p$} & \multicolumn{2}{|c|}{$\%$ of predicted values } & \multirow{2}{*}{$p$} \\
\hline & Before & After & & Before & After & \\
\hline $\begin{array}{l}\text { Vital capacity (l) } \\
\text { FEV, (l) }\end{array}$ & $\begin{array}{l}4.32(0.78) \\
3.23(0.74)\end{array}$ & $\begin{array}{l}4.12(0.92) \\
2.95(0.77)\end{array}$ & $\begin{array}{l}\text { NS } \\
<0.01\end{array}$ & $\begin{array}{r}95 \\
101\end{array}$ & $\begin{array}{l}84 \\
88\end{array}$ & $\begin{array}{l}<0.01 \\
<0.01\end{array}$ \\
\hline$F E V \%\left(\frac{\mathrm{FEV}_{1} \times 100}{\mathrm{VC}}\right)$ & $74.4(9.34)$ & $71.57(9.37)$ & NS & 107 & 108 & NS \\
\hline
\end{tabular}

NS-not significant.

Table 2 Spirometric results before and after operation in 25 patients: number with a $10 \%$ or greater change

\begin{tabular}{|c|c|c|c|c|c|}
\hline & \multicolumn{2}{|c|}{ Increase in volume } & \multicolumn{2}{|c|}{ Decrease in volume } & \multirow{2}{*}{$\begin{array}{l}\text { No of patients with changes } \\
\text { of }<10 \%\end{array}$} \\
\hline & No of patients & Mean $(S D)$ & No of patients & $\overline{\text { Mean }(S D)}$ & \\
\hline 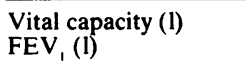 & $\begin{array}{l}2 \\
3\end{array}$ & $\begin{array}{l}1.4(0.3) \\
0.44(0.18)\end{array}$ & $\begin{array}{r}8 \\
15\end{array}$ & $\begin{array}{l}0.74(0.16) \\
0.56(0.36)\end{array}$ & $\begin{array}{r}15 \\
7\end{array}$ \\
\hline FEV $\%\left(\frac{\mathrm{FEV}_{1} \times 100}{\mathrm{VC}}\right)$ & 1 & 15 & 4 & $17(8.6)$ & 20 \\
\hline
\end{tabular}

The opacity looks like a recurrence of shrinking pleuritis with atelectasis and the patient is being kept under close observation.

Pleural fibrosis, seen on the radiographs as diffuse thickening of the parietal pleura, was present in 22 patients before operation. In these patients pleural plaques were observed during the operation. Radiologically these have remained unchanged after operation, except in one patient in whom the pleural changes have progressed.

The pleural and parenchymal abnormalities that have arisen in the immediate postoperative period, as a result of the thoracotomy and representing small atelectatic areas or small amounts of pleural exudate, have completely disappeared with the exception of obliteration of the costophrenic angle on the operated side in 11 patients. Appreciable hyperinflation of both lungs was present in the woman with asthmatic bronchitis. Malignancy has not been suspected in any of the patients. Classical parenchymatous asbestosis, as described by Soutar et al..$^{6}$ has not occurred in any patient.

\section{SPIROMETRIC EXAMINATIONS}

Before the operation all but two patients had spirometric volumes within normal limits. Two patients were operated on without prior spirometry. In the comparison between preoperative and postoperative values the two patients who had had a lobe resection were omitted, so the comparison comprises 25 patients (table 1). The number of patients with increase or decrease of the spirometric volume after operation is shown in table 2 . Most patients were in the lower half of the normal range, but eight and 15 of the patients were below the lower limits of normal for vital capacity and $\mathrm{FEV}_{1}$ respectively at the follow up examination.

The two men with improvement after surgery had shrinking pleuritis with atelectasis in the left and right lower lobe respectively, and the lobe was successfully expanded. In one of these patients there was appreciable compensatory emphysema in both the upper and the middle lobes at the operation. There were, however, other patients with very extensive lesions with less improvement after decortication.

There were four patients with more than a $20 \%$ decrease in spirometric volumes at the follow up examination. One of these patients was the woman with severe asthmatic bronchitis after operation. Another was the man with increased pleural thickening found at radiographic examination 12 years after surgery. He had no pulmonary symptoms. In the other two cases we could find no explanation for the decrease in function. The patients have no symptoms and the radiological appearances are satisfactory.

In a subgroup of seven patients whose spirometric values were obtained within two years of operation an increase was noted in two patients (mean $7 \%$ for $\mathrm{VC}$ and $10.5 \%$ for $\mathrm{FEV}_{1}$ ) and a slight decrease in five patients. The net effect was an insignificant decrease.

To see whether the asbestos exposure had affected the diffusion capacity of the lung, a carbon monoxide diffusion test was performed after operation in 14 patients and the results were normal in all but one. The nitrogen single breath test (giving a "nitrogen index") was performed after operation in 12 patients. The test measures the increase in nit- 
rogen concentration (\%) between the point at which the first $750 \mathrm{ml}$ have been exhaled and the point at which the next $500 \mathrm{ml}$ have been expired after a breath of oxygen has been taken. The result of this test was pathological in three patients: two showed a slight increase while one patient had a $6.9 \%$ increase in nitrogen concentration (upper limit of normal $2.9 \%$ ). This patient had a nitrogen test value of $6.9 \%$ just before operation and $5.4 \%$ two years before the operation. In the other two patients with the pathological result in the nitrogen test preoperative testing had not been done.

\section{Discussion}

Shrinking pleuritis with atelectasis is a condition that has been described under several names (the folded lung, ${ }^{2}$ pulmonary pseudotumour, ${ }^{3}$ round atelectasis, ${ }^{78}$ and pleuroma ${ }^{4}$. The reports concerned deal mainly with the radiological diagnosis and to some extent also with the aetiology, which is still unknown. To our knowledge there is no previous long term follow up of patients with this condition. There are also very few surgical series of cases of this disease, the largest being that of Payne et al ${ }^{10}$ (six patients). The treatment in general, the indications for operation, and the results of surgical treatment are not sufficiently elucidated in the published reports. As the decortication that was performed in most cases in this series did not influence the pathogenesis of the disease and is not likely to have acted on any causative factor, but only restored the normal anatomical conditions in the affected area of the lung, the long term results of this procedure were investigated with regard to (1) the clinical course of the disease after elimination of the atelectasis; (2) whether lung function and respiratory volumes were improved after re-expansion of the affected area of the lung; and (3) the risk of recurrence of the condition or development of a malignant lesion.

The symptoms of shrinking pleuritis with atelectasis seem to be entirely non-specific. Most cases reported seem to have been discovered at routine examinations; but dry cough, dyspnoea, or pleuropneumonic infection has occurred in some patients, as reported by several authors. ${ }^{27-4} 11$ We have not found that those patients with symptoms had more severe disease than the others. Symptoms may be explained by secondary, non-specific inflammatory complications developing in the atelectatic areas. The preoperative symptoms disappeared after operation in 18 of 19 patients. The operation thus seems to have a curative effect on symptoms. In those patients with new pulmonary symptoms at followup, they had started some time after the operation and could not be related to the operative procedure or to any pathological finding observed at the review.

At operation the large volume of the lung occupied by the lesion is often a striking finding, and after successful decortication the surgeon hopes that he has been able to increase the patient's functional pulmonary volume. Surprisingly, the effect of the operation on the spirometric volumes was a decrease in most cases. This decrease for the group as a whole is statistically significant, at least for absolute values of $F E V_{1}$. With a long interval between operation and follow up such a decrease could be explained by increasing age or intercurrent infection, which had occurred in many of the patients. Expressing spirometric volumes as a percentage of predicted values, however, takes the increase in age into consideration. Viewed in this way, there is a significant decrease in both VC and $\mathrm{FEV}_{1}$. Probably the increase in functional pulmonary parenchyma gained by the decortication is counteracted by a general restrictive effect of the thoracotomy. The results of nitrogen single breath and carbon monoxide transfer tests were normal in most cases, showing that uneven distribution of ventilation and impaired gas transfer are not common among these patients.

The parietal pleural plaques seen in most of these patients were not removed. If these plaques were a factor contributing to the development of shrinking pleuritis with atelectasis by causing local irritation, recurrence of the lesion would be expected. There were no recurrences in the same locations as the original lesion. There was, however, one recurrence in a patient who had many pleural plaques at operation, but it was located on the opposite side. Local irritation from plaques seems not to be an important factor in the development of this disease. Evidently the unknown causative factor can act for as long as nine years after the operation.

The radiological and spirometric follow up did not show signs of parenchymatous asbestosis or malignant degeneration in any of the patients in this series.

\section{References}

1 Dernevik L, Gatzinsky P, Hultman E, Selin K, William-Olsson G, Zettergren L. Shrinking pleuritis with atelectasis. Thorax 1982;37:252-8.

2 Blesovsky A. The folded lung. Br J Dis Chest 1966; 60: 19-22.

3 Tylén U, Nilsson U. Computed tomography in pulmonary pseudotumors and their relation to asbestos exposure. J Computer Assisted Tomography 1982; 6:229-37.

4 Bechlake MR. Asbestos related diseases of the lung and other organs: their epidemiology and implications 
for clinical practice. Am Rev Respir Dis 1976; 114: 187-227.

5 Buchanan WD. Asbestos related diseases. Part 1. In: Michaels L, Chissik SS, eds. Asbestos. Vol 1. Properties, applications and hazards. Chichester: John Wiley and Sons, 1979:403-4.

6 Soutar CA, Simon G, Turner-Warwick M. The radiology of asbestos-induced disease of the lungs. $\mathrm{Br} J \mathrm{Dis}$ Chest 1974; 68:235-52.

7 Hanke R, Kretzchmar R. Round atelectasis. Seminars in Roentgenology 1980;15:174-82.

\section{Book notices}

Pulmonary Rehabilitation: Guidelines to Success. Edited by JE Hodgkin, EG Zorn, and CI Connors. (Pp 426; £50.) Butterworth. 1984.

Chest physicians, members of related professions, and interested lawyers and accountants will find much that is worthwhile in this book. There are 54 contributors but the 24 chapters read well and there is little duplication. Opening chapters outline the organisation of the service, the initial assessment of the patient (financial as well as medical), and the legal contract which he and a near relative must sign. Ethics, marketing, and cost-benefit analysis come later. Thirteen chapters provide detailed practical information on preventive care, abandoning smoking, respiratory pharmacology, inhalation treatment, breathing techniques, daily activity, exercise therapy, psychotherapy, sexuality, nutrition, vocational rehabilitation, and home care, including that of the patient on a ventilator. The chapter on drug treatment is descriptive but apparently definitive, and it is not made clear that some treatments are or should be obsolete. Abandoning smoking is desirable, not mandatory. Exercise therapy reflects practice in cardiology. There are few recent references to European publications; this is not important, however, as the book seems to be directed to the commercial medical market, which is mainly the United States.-JEC

Pulmonary Nuclear Medicine: Techniques in Diagnosis of Lung Disease (Lung Biology in Health and Disease
8 Schneider HJ, Felson B, Conzales LL. Rounded atelectasis. AJR 1980;134:225-32.

9 Sinner WN. Pleuroma-a cancer-mimicking atelectasic pseudotumor of the lung. Fortschr Röntgenstr 1980; 133:578-85.

10 Payne CR, Jaques P, Kerr IH. Lung folding simulating peripheral pulmonary neoplasm (Blesovsky's syndrome). Thorax 1980;35:936-40.

11 Brune J, Bosly A, Bory R, Perinetti M, Wiesendanger T, Galy $P$. Condensations parenchymateuses pulmonaires arrondies post-pleuretiques. Mecanisme physiopathologique. Lyon Medical 1974;231:605-9.
Series_volume 23). Edited by Harold L Atkins. (Pp 386; $\$ 69.75$ US and $\$ 83.50$ Canada, or SFr 193 all other countries.) Marcel Dekker Inc. 1984.

It is hard to see for whom this book is written. It contains a wealth of technical detail on how to perform lung imaging of studies in the investigation of pulmonary embolism, obstructive and infiltrative lung disease, pneumoconiosis, lung cancer, and paediatric lung disease. There is a further section on the interrelationships between heart and lung disease and imaging. The technical problems of nuclear imaging are certainly interesting but of practical benefit only in the chapter discussing the use of nuclear imaging in pul- $\overline{\bar{O}}$ monary embolism. The sections on pulmonary embolism $\exists$ and the role of gallium scanning in interstitial pulmonary $\vec{\partial}$ disease are very informative. The large numbers of excellent illustrations of scans in different types of obstructive and interstitial lung disease are mainly irrelevant to clinical management. Each chapter starts with abbreviated accounts of the major diseases to be discussed-for example, five lines on the pathology of asthma. There is also a 28 page chapter on simple physiology, which seems unnecessary in a book of this type. It is claimed that the volume will be found useful by nuclear medicine trainees and radiologists; but it is doubtful whether, apart from two 음 chapters, it will be of interest to practising physicians. It is not clear why this distinguished series has devoted a whole volume to this particular topic.-SGS 